\title{
GENDER DIFFERENCES IN THE RELATION BETWEEN BINGE DRINKING AND VIOLENCE
}

\section{Nomonde Phetlho-Thekisho, Elma Ryke, Herman Strydom}

\section{INTRODUCTION}

Alcohol use is a global phenomenon. The practice has been present in African social life for centuries as it has also been in other parts of the world, either as a form of entertainment, bonding, confidence boosting, relaxation and euphoria, except in instances where it is outlawed for religious purposes, such as in predominantly Muslim communities. Large quantities of brewed or distilled drinks are often produced in local communities or commercial enterprises to meet the demands of consumers (Meel, 2006:1; Obot, 2006:17).

Alcohol consumption patterns differ from one setting to another. For instance, globally the annual per capita consumption was approximately five litres of ethanol per person in the adult population in 2006. The highest level of drinking by adults in the world was reported to be in Europe, where adult per capita consumption has been increasing for more than two decades. In Africa the average consumption was about four litres of alcohol, per adult population, whereas in South Africa it was estimated that the per capita alcohol consumption was between 10.3 and 12.4 litres, with the highest level reflecting the amount including home-brewed alcohol (Obot, 2006:20; Parry \& Dewing, 2006:42). Per capita alcohol consumption denotes the level (average volume) of alcohol consumption per adult per year. Alcohol consumption patterns on the other hand show whether or not the drinking in a country is hazardous (Obot, 2006:21).

As is evident, South Africa falls into the group of countries displaying the most hazardous pattern of drinking, sometimes termed binge or risky drinking. Apart from health problems, binge drinking also manifests in different kinds of social ills (Parry \& Dewing, 2006:42).

Reviews (WHO, 2004:2; WHO, 2006a:2) have found that excessive alcohol use can be a strong and consistent correlate of violence between men and women. According to Kalichman and Simbayi (2004:682), South Africa reportedly has one of the highest rates of violence against women in the world. To illustrate this point, research undertaken by the Medical Research Council revealed that one in four women in the general South African population has experienced physical violence at some point in their lives. A national study on female homicide further indicated that a woman is killed by her partner every six hours. Studies have also found that the risk of intimate partner violence is highest in societies such as South Africa, where violence seems a socially sanctioned norm (Lau, 2009:1).

It is against this background that the study in this article reviews the literature on gender difference and its relation to binge drinking and violence, using the ecological approach as a conceptual framework for understanding risk factors associated with alcohol-related violence.

\section{CONCEPTUALISATION}

\section{BINGE DRINKING}

The term binge drinking can mean different things to different people. Previously the term is said to have meant a pattern of heavy drinking that occurs over an extended period set aside for this purpose. However, it is now commonly used to describe a drinking session that encompasses consumption above a given cut-off level of alcohol. This cut-off level can differ from one setting to another. Occasionally this type of alcohol consumption pattern is also 
referred to as harmful, hazardous and episodic heavy drinking. In the South African situation binge or risky drinking for males means drinking five or more drinks (units) per day, and for females as drinking three or more drinks (units) per day. Furthermore, hazardous drinking will be indicated by the level of the population drinking first thing in the morning, drinking to intoxication, drinking apart from meals ${ }^{1}$ and drinking on weekends (Odejide, 2006:42; WHO, 2004:1). The terms risky, hazardous, binge, heavy episodic drinking, and excessive drinking will be used interchangeably in this review.

Binge drinking is different from intoxication, which is defined as "a condition that follows the administration of alcohol and results in disturbances in the level of consciousness, cognition, perception, judgment, affect or behaviour, or other psycho-physiological functions and responses" (Anderson, 2008:15).

\section{INTERPERSONAL VIOLENCE}

Interpersonal violence is divided into two sub-categories, namely family and intimate partner violence, which is violence largely between family members and intimate partners that usually, though not exclusively, takes place in the home. Community violence, on the other hand, is violence between individuals who are unrelated and who may or may not know each other. This type of violence generally takes place outside the home (Dahlberg \& Krug, 2002:5). In this review both intimate partner and community violence are referred to.

\section{VIOLENCE}

The World Health Organisation defines violence as "the intentional use of physical force or power, threatened or actual, against an individual, group or community, that either results in or has a high likelihood of injury, death, psychological harm, impaired development or deprivation" (Dahlberg \& Krug, 2002:4). Although violence may be carried out by both genders, the view that women are more likely to be victims applies in this article.

\section{THE ALCOHOL-VIOLENCE LINK}

There is no doubt that alcohol is a factor in many men's violent behaviour directed at women. However, there is also no conclusive evidence that alcohol directly causes violent behaviour. Existing research points to an association only, together with an increased risk of violence when the male perpetrator has been drinking (Galvani, 2004:358). Studies on violence have shown that alcohol consumption commonly precedes violent events, and that the amount of drinking is related to the severity of subsequent violence (Felson \& Burchfield, 2004:837). As an illustration, the following are numerous mechanisms highlighted by the WHO (2006b:4-5) showing circular causality.

- Alcohol use directly affects cognitive and physical functioning. Reduced self-control and ability to process incoming information makes drinkers more likely to resort to violence in confrontation (for example, youth violence), and reduced ability to recognise warning signs in potentially violent situations makes victims easy targets for perpetrators (for example, sexual violence).

- Individual and societal beliefs that alcohol causes aggressive behaviour can lead to the use of alcohol as a way of excusing violent acts (for example, intimate partner violence).

\footnotetext{
1 The writers do acknowledge the difficulty in contextualising this aspect of binge drinking in predominantly poverty stricken communities in which food scarcity is common.
} 
- Dependence on alcohol means that individuals may fail to fulfil care responsibilities or it can cause them to extort money from relatives to purchase alcohol (for example, abuse of older persons).

- Experiencing or witnessing violence can lead to the use and misuse of alcohol as a way of coping or self-medicating (for example, as a consequence of child abuse).

- Prenatal alcohol exposure (resulting in foetal alcohol effects) is associated with behavioural and social problems, including delinquent behaviour, sexual violence and suicide in later life.

\section{THE ECOLOGICAL APPROACH TO UNDERSTANDING RISK FACTORS OF ALCOHOL-RELATED VIOLENCE}

\section{BACKGROUND TO THE ECOLOGICAL APPROACH}

The ecological approach focuses on the relationship and reciprocal and adaptive transactions among organisms (for example, a person, couple, family, group, organisation, communities or larger societal structures) and their bio-, psycho-, socio-cultural as well as economic, political and physical environment (Weyers, 2011:17). Bronfenbrenner in Greene (2008:199) has also defined the ecological approach to human behaviour as the "scientific study of the progressive, mutual accommodation throughout the life course between an active, growing human being and his or her environment". Greene (2008:199) sees the approach as a broad framework that synthesises ideas from a number of human behaviour and social work practice theories and a perspective that offers a rich, eclectic social work knowledge and practice base.

By environment reference is made to the psychological environment, which is abstract by nature and consists of the attitudes people acquire and display towards others around them, based on life experiences. The social environment involves the way that communities are structured and how people relate to one another (interact); one also notes, as part of the social environment, the importance of understanding the impact of negative forces within communities on people, such as delinquency, crime, violence and alcohol abuse. The cultural environment determines the norms and values of people and it can also be adapted or changed by people as the need arises. ${ }^{2}$ Culture creates or contains taboos and provides a framework according to which people act and react to daily life. The economic environment determines the economic context, which can refer to the rate of employment/unemployment, presence and activity of commerce and industry, and the presence and scope of informal economic activity. The political environment can involve different power structures such as traditional or democratic structures. Political systems and parties, policies, legislative and state institutions are also examples of the political environment; within this type of environment the issue is gaining access to resources to satisfy needs. With the physical environment the emphasis is on habitat, infrastructure, natural resources and climatic conditions; for example, a lack of food crops will in turn affect the health of communities (Swanepoel \& De Beer, 2004:6-10; Weyers, 2011:17).

Despite questions about the clinical usefulness of the ecological model, its strength as used in this review is that it helps to distinguish between the myriad of influences on alcohol-related

${ }^{2}$ However, on the whole in most communities, including some of those in South Africa, culture remains static. 
violence, while at the same time providing a framework for understanding how they interact (WHO, 2002:9).

\section{RISK FACTORS ASSOCIATED WITH ALCOHOL-RELATED VIOLENCE}

In an attempt to understand the risk factors associated with alcohol-related violence, Heise (Scottish Government Publications, 2005:2) suggests that there may not be one single "cause" but rather a whole range of variables which can increase or reduce a woman's risk of experiencing violence, especially violence related to alcohol. It must, however, be acknowledged that risk factors are not the same as causes, and that the risk factors are complex and occur at different levels. The four levels are represented as embedded concentric circles in Figure 1.

\section{FIGURE 1 \\ ECOLOGICAL FRAMEWORK}

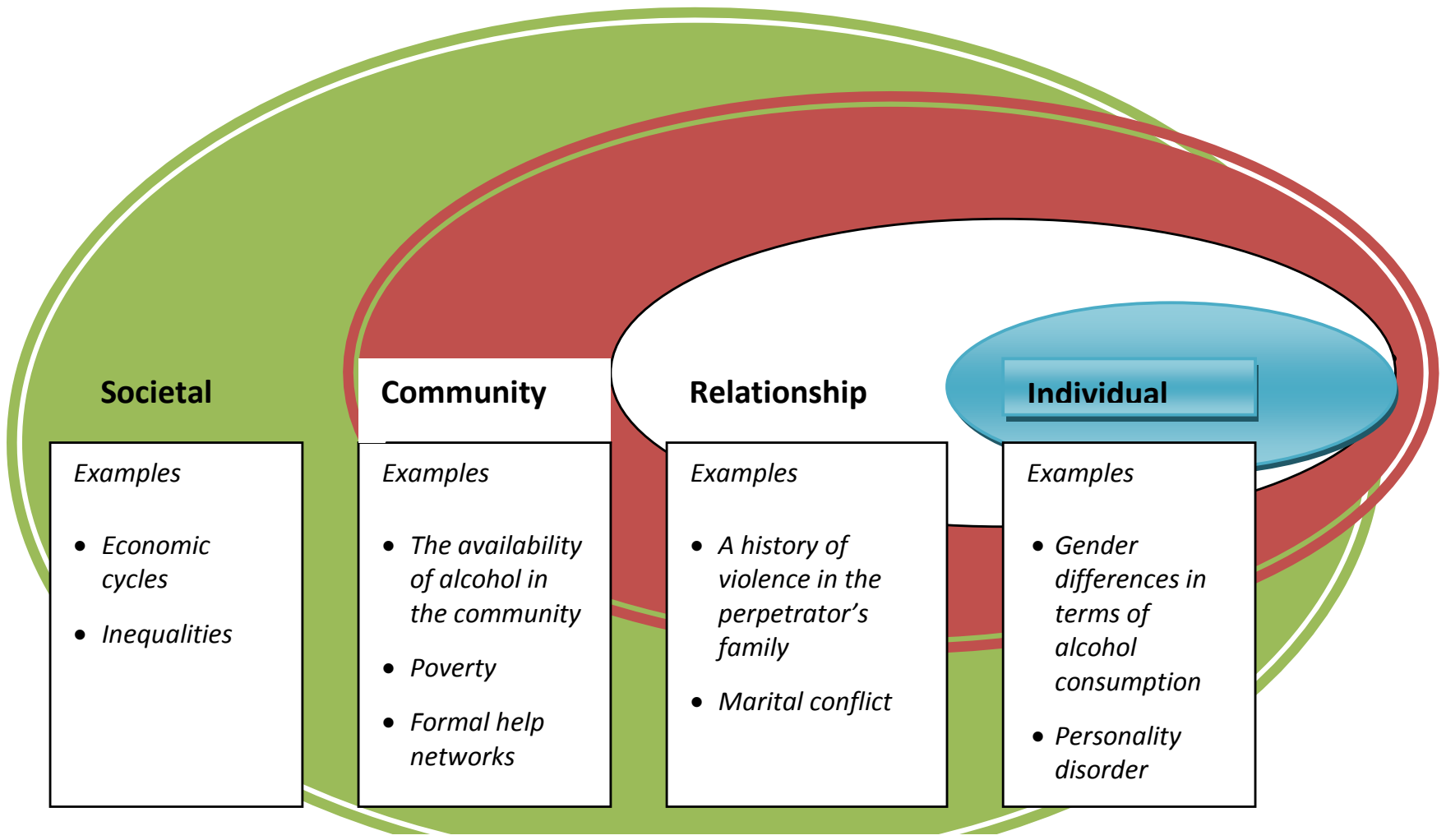

Source: WHO - World Report on Violence and Health, 2002.

The presentation of the risk factors associated with alcohol-related violence from either side is significant. However, in this article the presentation is from the individual to societal level in order to emphasise the individual as being core to the model.

According to Figure 1, the innermost circle identifies biological and personal factors that influence how individuals behave and increase their likelihood of becoming a victim or perpetrator of violence; personality disorder and alcohol abuse serve as examples. The second level focuses on close relationships, such as those with family and friends. In youth violence, for example, having friends who engage in or encourage violence can increase a young person's risk of being a victim or perpetrator of violence. For intimate partner violence, the 
most consistent marker at this level of the model is marital conflict or discord in the relationship. In elder abuse, important factors are stress as a result of the nature of the past relationship between the abused person and care giver, or overcrowded living conditions. The third circle represents the community within which people interact and within which institutions and social structures (both formal and informal) exist that perpetuate the occurrence of alcohol-related violence. The outer layer of the model represents the society within which general views and cultural beliefs make alcohol-related violence acceptable (Betron \& Doggett, 2006:16; Krug et al., 2002:1085). A further analysis of these multiple factors follows below.

\section{INDIVIDUAL FACTORS}

This level seeks to identify the personal factors that an individual acquires. In other words, this level focuses on aspects of the individual that tend to increase the likelihood of their either being a victim and/or a perpetrator of violence such as in alcohol use by men as perpetrators

The differences in gender behaviour may stem from the socialisation process of both the boy and the girl child, which appears varied in most communities worldwide. Research by Boonzaier and De la Rey (2004:454) indicates that femininity has traditionally been constructed as nurturing, caring and selfless. Women are mostly construed as the providers of love and care, often putting their partners' needs before their own - a form of subservience. Boy children, however, seem to go through a process which appears to encourage them to suppress their feelings, to be competitive and aggressive, to be in charge and tough, and to take risks. A macho masculine mystique is promoted. The possible end product of such a socialisation process often presents as stubbornness and being perpetually virile breadwinners of their families, and who are aggressive towards women, other men and to themselves (Heery, 2001:24-25). Boonzaier and De la Rey (2004:454) further found that some men socialised in this way take pride in the fact that they always provide for their families despite financial disagreements or struggles - a form of masculinity which gives them ownership of their families, including their female partners. The question arises: Are women collaborators in their oppression as agents of socialisation, or are they merely repeating what was done to them? Thus a vicious cycle is set in motion.

In societies where such traditional gender roles are observed and entrenched, the result has been unequal gender relations. As an illustration, some cultural practices in South Africa still expect women, despite constitutional provisions, to defer to men in decision making in both the public and the private spheres. As a result most women tend to experience obstacles in entering corporate management and other decision-making positions, including public office. Those women who have penetrated decision-making structures (seemingly transgressing traditional gender roles) tend to find the environment sexist and are often forced to leave. In such a climate of emotional abuse most women affected tend to resort to alcohol as a way of coping, or to selfmedication (South Africa's National Policy Framework for Women's Empowerment and Gender, 2000:17; WHO, 2006b:2). Based on the apparent gender division of resources and opportunities, constitutional changes in South Africa thus appear to have changed the position but not the condition of women (and the term "women" does not imply a homogeneous category).

Furthermore, discriminatory practices liable to be interpreted as double standards practised in relation to women also are evident in the criminal justice system of most societies. A South African study (Padayachee, 2003:111) showed that women who are seen as "problem drinkers" are often viewed by the courts and society as more unacceptable than men who engage in the 
same behaviour. Society tends to see an alcohol-abusing woman as doubly deviant, for she has transgressed not only the law or general social convention, but violated the norms of being a good woman. Her drinking tends to render her subject to immediate and often unsubstantiated suspicions of incompetence as a woman, mother and, most importantly, a wife - a form of emotional abuse which can result in personality disorder. At the individual level the issue is the degree to which women and men have internalised these societal expectations.

A review by Phorano et al. (2005:198) found that in most of the cases they studied violence in the household seemed to be alcohol-related. Alcohol abuse and the related violence are reported to have increased at weekends and month-ends, when working men receive their wages and salaries. A positive explanation for the relationship between alcohol abuse and intimate partner violence is that drunkenness for men seems to have become an acceptable condition for venting frustration and anger, which seem to be suppressed when they are sober. Also, traditional practices of resolving conflicts through the extended family structures do not seem to work when one is drunk. Some research (Betron \& Doggett, 2006:18) has also shown that men use alcohol as an aid in their violent actions. Findings suggest that some men feel less accountable for their violent actions when drunk, while others intentionally use alcohol to enable them to beat their partners, which they feel is socially expected of them. It also seems more likely that alcohol reduces inhibitions, clouds judgment and impairs the ability to interpret social cues, thereby making some men who are predisposed to violent behaviour more likely to engage in violence, including violence against women. It should be noted that there is no conclusive evidence that alcohol directly causes violent behaviour. Existing research points to an association only, together with an increased risk of violence when the male perpetrator has been drinking (Galvani, 2004:358).

\section{RELATIONSHIP FACTORS}

This level explores how relations with peers, intimate partners and family members can increase the risk of violent victimisation and perpetration of violence. Relationship dissatisfaction can strengthen the links between problem drinking and partner violence. Some evidence suggests that couples where only one partner (the man) drinks excessively are more likely to experience alcohol-related arguments and physical violence (WHO, 2006a:4). Such behaviour can affect the family and children negatively in several ways.

\section{LEARNING WITHIN THE FAMILY OF ORIENTATION}

Violence can be an acquired behaviour. For instance, a boy child growing up in a family may observe his father being violent toward his mother. He may learn that such behaviour gets his father what he wants, and that he in turn can become violent to get what he wants. Over time such deviant behaviour may be self-reinforced. Not all children from similar situations will internalise such deviant behaviour, though. Other children do remain well adjusted despite growing up with abuse (Heery, 2001:23).

Exposure to parental violence during childhood can also serve as a risk factor for alcohol dependence and other alcohol-related problems later on in life, and parental alcohol consumption, especially by the mother, increases the risk of violent offences among children (WHO, 2005:4). Explanations for this acquired behaviour are reflected in the social learning theory. According to Renzetti et al. (2001:6), the social learning theory is one of the most popular explanatory frameworks for alcohol-related violence against women, suggesting that individuals learn how to behave through both experience of, and exposure to, alcohol-related violence. When individuals observe or imitate behaviour, they learn what those around them 
consider appropriate. The social learning theory also uses the concepts of classical conditioning, instrumental or operant conditioning, and modelling (Levin, 1995:175). With classical conditioning new behaviours are acquired by being paired with other behaviours consistently and over time. This entails the coupling of an unconditioned stimulus with a conditioned stimulus to produce a conditioned response. Drinking alcohol can be paired with an unconditioned stimulus (violence) and can become a conditioned stimulus for consumatory behaviour. As a result, the drinker has learned to be violent when intoxicated.

Operant conditioning, on the other hand, is a type of learning in which behaviours are influenced primarily by the subsequent results. What follows a particular behaviour determines how that behaviour will recur, as in either positive or negative reinforcement. With modelling, learning occurs by observing others, which means the behaviour can only be learned through observation of its occurrence (Levin, 1995:176). As Levin (1995:178) puts it, the social learning theory teaches that other people's behaviour is a powerful influence on individuals. Apart from the home serving as a learning environment, culture and the media also seem to provide a number of models for violence (Galvani, 2004:359).

A study by Heery (2001:24) has also elucidated the negative effects on children of having no positive, committed fathers in their lives. ${ }^{3}$ There are apparently key tasks for fathers to help boys move through developmental stages, which include managing aggression and anger, mentoring and protection against violence and aggression.

\section{MARITAL CONFLICT}

As would be expected, marital conflict is a major risk factor for intimate partner violence. In South Africa women with frequent general conflict in their relationships were nearly 17 times as likely to experience alcohol-induced violence in the past year of their marriage (Betron \& Doggett, 2006:20-21). For instance, in Kenya women who were divorced or separated, presumably as a result of marital conflict, were more than four times as likely to have experienced sexual coercion which was alcohol related. Kenyan women are also said to have cited conflict about money as the leading cause for alcohol abuse and intimate partner violence (Betron \& Doggett, 2006:20-21).

Studies (WHO, 2006a:3) of intimate partner violence against women routinely identified recent consumption of alcohol by men as perpetrators. Estimates vary among countries. In Australia, $36 \%$ of intimate partner homicide offenders were under the influence of alcohol at the time of the incident, while in Russia $10.5 \%$ of such offenders were intoxicated. In South Africa $65 \%$ of women experiencing spousal abuse within recent months reported that their partner always or occasionally consumed alcohol before the assault. The question is whether "premeditation" supersedes the question of "aggravating circumstances" in a court of law.

\section{COMMUNITY FACTORS}

This level examines the community contexts in which social relationships are embedded and influenced by factors such as those outlined below.

\footnotetext{
${ }^{3}$ The phenomenon of absent fathers is common in most communities including those in South Africa. The situation has been exacerbated by the pandemic of HIV and AIDS which has resulted in many families being child-headed and without adult role models.
} 


\section{THE AVAILABILITY OF ALCOHOL IN THE COMMUNITY}

Greater concentrations of drinking venues within an area have been found to increase the risk of interpersonal violence in that area, particularly against women in the form of sexual assault. The alcohol-related assaults most frequently occur at night and particularly on weekend nights (WHO, 2006b:7).

In some African communities alcohol is available every day to the old as well as the young. It is not only formally produced but also informally manufactured (home brews) and sold in public drinking places such as shebeens. ${ }^{4}$ This availability has a major influence on the overall alcohol consumption, which manifests in the following ways:

- Drinking at the work place;

- Experimenting with alcohol by young people who drink at school;

- Drinking at every gathering, such as at parties, funerals and formal meetings (Buning, 2006).

In most South African communities alcohol is freely available through an estimated 230000 liquor outlets. This availability of alcohol accounts for South Africans consuming more than 5 billion litres per year, often resulting in risky sexual behaviour, family and public violence, and trauma (Health24, 2000-2009:1).

In most of the cases these liquor outlets are predominantly situated in impoverished communities. According to the Gauteng Provincial Draft Liquor Policy document (2011:11), when comparisons were drawn between two regions in the Johannesburg area, the results revealed that in Region A (Rosebank), which is predominantly white and affluent, there are about 16 shebeens, 302 licensed liquor outlets and 623 people per liquor outlet; in Region B (Freedom Square), which is predominantly black and impoverished, the figure was 2438 shebeens, with 123 licensed liquor outlets and 414 people per liquor outlet. Research (Hungerford, Anderson, Hughes, Bellis, Anderson, \& Abbey, 2008:2) shows that young women who visit bars frequently are most at risk of being victims of sexual aggression in nightlife environments, whereas men are more likely to initiate acts of sexual violence. However, the risk of being victimised increases for both genders following heavy alcohol consumption, which can reduce their ability to interpret warning signs, make them less able to defend themselves and reduce their risk perception and consequently safety behaviours. More or less half of sexual assaults are related to alcohol and in most alcohol-related cases both the victim and perpetrator had been drinking.

\section{POVERTY}

Categorising poverty under any one of the levels of the ecological model would be relevant. However, in keeping with the model, it is discussed here under community factors. According to Betron and Doggett $(2006: 21)$, evidence points to the fact that poverty may also be considered an individual, relationship or societal factor. In settings as diverse as the United States, Nicaragua and India, violence is more frequent in lower socio-economic groups, pointing to the significance of poverty as a community and societal risk factor (Betron \& Doggett, 2006:21).

\footnotetext{
${ }^{4}$ Shebeens are private homes where alcoholic beverages are sold and served on or off premise. On the whole, shebeens are unlicensed and are usually run by women, often known as shebeen queens (Morojele et al., 2006:220).
} 
In the South African situation black rural women are still the poorest in society, despite constitutional and policy changes as forms of empowerment. Most of these black rural women seem generally invisible in the economy. If economically active, they seem clustered in the lower echelons of the informal sector. They occupy the most labour-intensive, under-valued and lowest-paying jobs - rendering them dependent on their male partners. Many of these women live in rural and informal settlements, where there is often no basic infrastructure, such as a court house or a legal aid centre. This situation often renders them helpless in cases of violence. Many are also illiterate, especially in terms of the language used in the justice system (South Africa's National Policy Framework for Women's Empowerment and Gender, 2000:11). Such discriminatory situations are said to contribute to depriving most women of access to power and self-determination, despite South Africa's social and labour policies on affirmative action and gender equality. Such practices have also been recognised as catalysts for many women resorting to alcohol use to numb their pain. Many women living in abusive relationships are also said to have admitted that they had succumbed to the temptation of alcohol "to put an acceptable gloss on their lives" (Padayachee, 2003:108).

\section{FORMAL SUPPORT SYSTEMS}

Formal support systems are mostly officially sanctioned by society. They often have stable organisational structures and resources that enable them to render services to the community, and have either legal or moral power to influence people, such as the police, criminal justice system, faith-based organisations, social workers and health care workers. Such formal networks can occasionally be ineffective, especially in rendering assistance to abused women. In certain instances the attitudes of the service providers can in fact victimise the abused women for the second and subsequent times. For instance, the process of laying a charge and pursuing a case through the criminal justice system is likely to be taxing for victims especially. The process can be riddled with insensitivity, disrespect and harsh treatment from service providers, which may serve as a source of additional distress for the victim (Bruce, 2007:102).

The inadequate response from most of the law enforcement agencies that tend to view intimate partner violence as a family matter outside their mandate and jurisdiction can also be a discouraging factor for battered women. Even though there are policies against intimate partner violence in the statute books (such as the Domestic Violence Act, 116 of 1998; the Promotion of Equality and Prevention of Unfair Discrimination Act, 4 of 2000; and the Maintenance Act, 99 of 1998), lethargy in its enforcement has been common (Artz \& Smythe, 2007:131-132).

As an illustration of non-implementation of some policies meant to protect women from abuse, research (Artz \& Smythe, 2007:140) has shown that some law enforcement personnel are reluctant to grant protection orders on the basis of sexual abuse, economic abuse, and psychological or emotional abuse. They are often said to require physical abuse to be present before they grant relief. Psychological and emotional abuse are often not considered imminently harmful. The findings indicate that the intentions of the new policies are rarely translated into effective remedies that alleviate the problem. Such behaviour signifies lack of training and sensitivity on the part of some service providers - thus adding an extra burden to already burdened women. This can also be a stress factor for the victimised women - signifying a poor environmental fit.

\section{SOCIETAL FACTORS}

Included here are those factors that seem to create an acceptable climate for alcohol-related violence in a particular society, such as South African society. 


\section{ECONOMIC CYCLES}

Economic cycles are fluctuations in the economy, often determined by either economic growth or relative stagnation or decline in the economy. In most settings of low-income households, gender violence may be increasing because of rapidly changing roles that are determined by economic cycles. Currently there seems to be increasing economic pressure on poor households, with men in many parts of the world having lost their traditional occupations and jobs. Women have been forced to take on or increase their income-earning activities in addition to their domestic tasks. The relative increase in women's economic power, combined with men's unemployment, seems to have created feelings of humiliation and emasculation among most men and a sense of loss of control within their households. These feelings of frustrations and anger from men not being able to fulfil their traditional roles as breadwinners often lead to increasing levels of tension and alcohol-related violence directed against members of their families, particularly their intimate partners (WHO, 2005:13).

As an illustration, men from Lesotho have for generations come to South Africa's mines to work, sending money home to their wives. But in the last decade, as mines have closed, thousands have lost their jobs. This has led to growing alcohol-related violence as men, stuck at home and unable to find work, take their frustrations out on their families. As a result many women in Lesotho have become the breadwinners of their families, taking low-paying jobs as domestic workers or in textile factories. While many turn their salaries over to their husbands, others rebel, demanding that the family's few spare cents go towards buying food rather than alcohol (Goering, 2004:3).

\section{INEQUALITIES}

Another constellation of factors at societal level that tends to place people at risk of becoming perpetrators of alcohol-related violence and/or victims is inequitable relations, either in terms of gender, race, domicile or sexual orientation. Emphasis is, however, placed on geographical inequalities (Chopra \& Sanders, 2004:158).

In South Africa almost half of the population is living in rural traditional homesteads. In most of these rural areas people are engaging in declining subsistence production. Most people are also relying increasingly on welfare grants, casual and seasonal jobs with remitted wages for survival - a situation which does affect their dignity and personhood (Chopra \& Sanders, 2004:158). There are farming communities within these rural areas. One of the most striking problems on farms is the lack of infrastructure and public services, which tends to exclude most farm workers from economic activities, health services and educational opportunities. Most farming communities are located far away from towns, without a reliable and regular public transport system in place (Kruger et al., 2006:833).

A common feature of most urban areas in South Africa is informal settlements. These are nondesignated areas for human occupation. The land on which people live is in most cases not serviced and consequently lacks basic amenities such as running water, electricity and sanitary services. According to Harsch (2001:12), in these areas the shacks in which people live are tiny, the pathways between them are narrow and lined with open gutters. Virtually all inhabitants are unemployed.

As a way of demonstrating inequalities, by contrast suburbs in South Africa remain largely white and affluent. The suburbs boast everything that informal settlements and rural communities do not have, such as large and spacious houses and a high tax base to support 
ample amenities and services. Residents in these suburbs are mostly protected by walls, electrified fencing and private security firms being constantly on patrol (Harsch, 2001:12).

Since the democratic elections in 1994 in South Africa most policies on paper are formally colour-blind and gender sensitive. In reality South Africa still remains an inequitable society. Although disparities have narrowed somewhat, the country's income distribution is still among the most unequal in the world. Alongside displays of prosperity rarely seen anywhere in Africa, millions of South Africans still live below the poverty line, many of them seething with anger and frustration (Harsch, 2001:12).

Much as this does not mean that advantaged communities such as those living in suburbs are exempted from alcohol-related violence, high levels of alcohol-related violence have been reported among residents of disadvantaged societies (Meel, 2006:2). A high prevalence of alcohol-related violence within a particular community can also further affect the quality of life, reduce community cohesion, increase fear of crime and prevent people from visiting such places, which are associated with disorder and crime. Easy targets of such anomie are commonly women and children, who endure sexual assaults (WHO, 2006b:8).

\section{DISCUSSION AND CONCLUSION}

This review has traced the relationship of gender differences to binge drinking to violence. Gender differences, including discrimination against women, still predominate in most countries, including in South Africa, where the South African Constitution and the Bill of Rights promote women's rights as human rights, with explicit reference to gender-based violence and to women being free from all forms of violence from either public or private sources; yet women are daily plagued by violence in all forms. There seems to be a gap between what Padayachee (1998:57) terms "paper rights" and "real rights". The gender differences are socio-culturally entrenched through the gender division of labour, opportunities and resources.

The review has also established that there is a link between binge drinking and violence. However, studies have shown that there is no conclusive evidence that alcohol directly causes violent behaviour. Existing research points to an association only, together with an increased risk of violence when the male perpetrator has been drinking (Galvani, 2004). In other words, the link does not imply linear causality, instead circular causality is posited. The ecological model used has demonstrated that violent behaviour grows from a complex interplay of individual, relational, communal and societal dynamics.

As noted by Jewkes (in Betron \& Doggett, 2006:18), there are flaws in the ecological practice model designed by Heise, and that should be noted by interventionists. Some risk factors could fit at multiple levels. There also seem to be conceptual problems in defining the difference between "community" and "society". Several risk factors can indeed be placed at more than one of the levels; for example, "poverty", as cited under community, can be an individual as well as a societal risk factor. Likewise, many factors at the community and societal levels may be interchangeable. Nonetheless, it can also be argued that these apparent flaws within the ecological model simply reflect the complex way in which risk factors related to violence against women interact.

The conceptualisation of violence offers a framework for understanding the manifestation and mechanisms of different power relations between men and women, and control of women by men in an intimate partner relationship. These mechanisms can include factors such as 
intimidation, using male privileges, and threats. These mechanisms may also be used to try to understand socio-cultural expressions of power and control over women.

What is moreover evident from the review is that men's use of violence against their intimate partners and their abuse of alcohol can be associated with having learned and witnessed such behaviour from the family of origin. The question of the availability, affordability and accessibility of alcohol and alcohol drinking places in most communities features strongly in this review as a community risk factor to alcohol-related violence against women, while feelings of helplessness and powerless on the part of men not being able to fulfil their traditional roles as breadwinners are seen as increasing the levels of tension and alcohol-related violence against members of their families. Men are socialised into being violent - a factor which can sometimes be interpreted as the collaboration of women in their own discrimination and oppression.

In conclusion, a number of key issues emerged from the investigation for consideration in intervention and these are summarised as follows:

- There is a need for acknowledgement by policy makers and interventionists that, since alcohol-related interpersonal risk factors are socio-culturally constructed, change is possible - meaning that these factors can either be reconstructed or deconstructed.

- The myriad of alcohol-related violence risk factors identified calls for a holistic intervention based on the involvement of all sectors of the population - a multi-disciplinary team, including both the survivors and perpetrators of alcohol-related violence. The intervention programmes are to be tailor-made in line with community dynamics and addressing issues of poverty, unemployment, alcohol-consumption patterns and whether a community is a rural or/and urban one.

- At the individual and relational levels, challenging people's attitudes, beliefs, perceptions and behaviours related to binge drinking and violence against women requires a great deal of sensitivity to socio-cultural dynamics.

- For effective intervention the active involvement of the survivor and perpetrator is also paramount and should be emphasised by the interventionist.

- Community-based programmes to change discriminatory gender norms can be implemented, followed by human rights advocacy to foster gender equality and the empowerment of women.

\section{REFERENCES}

ANDERSON, P. 2008. A report on binge drinking and Europe. Germany: German Centre for Addiction Issues.

ARTZ, L. \& SMYTHE, D. 2007. South African legislation supporting victim's rights. In: DAVIS, L. \& SNYMAN, R. (eds) Victimology in South Africa. Pretoria: Van Schaik Publishers.

BETRON, M. \& DOGGETT, E. 2006. Linking gender-based violence research to practice in East, Central and Southern Africa: a review of risk factors and promising interventions. Publication produced for review by the United States Agency for International Development. Unpublished. 
BOONZAIER, F. \& DE LA REY, C. 2004. Women abuse: the construction of gender in women and men's narratives of violence. South African Journal of Psychology, 34(3):443463.

BRUCE, D. 2007. Challenges of the criminal system in addressing the needs of victims and witnesses. In: DAVIS, L. \& SNYMAN, R. (eds) Victimology in South Africa. Pretoria: Van Schaik Publishers.

BUNING, E. 2006. Third International Conference on alcohol and harm reduction creating realistic and concrete solutions. Cape Town, South Africa, October 22-25.

CHOPRA, M. \& SANDERS, D. 2004. From Apartheid to globalisation: health and social change in South Africa. [Online] Available: www.ep.liu.se/ej/hygiea/ra023/paper.pdf. [Accessed: 12/03/2009].

DAHLBERG, L.L. \& KRUG, E.G. 2002. Violence - a global public health problem. In: KRUG, E.G., DAHLBERG, L.L., MERCY, J.A., ZWI, A.B. \& LOZANO, R. (eds) World report on violence and health. Geneva: World Health Organization.

FELSON, R.B. \& BURCHFIELD, K.B. 2004. Alcohol and the risk of physical and sexual assault victimization. Criminology, 42(4):837-859.

GALVANI, S. 2004. Responsible Disinhibition: alcohol, men and violence to women. Addiction Research and Theory, 12(4):357-371.

GAUTENG PROVINCIAL DRAFT LIQUOR POLICY. 2011. Responsible Distribution Promotion Sale and Consumption of Liquor. Department of Economic Development. Unpublished.

GOERING, L. 2004. In Lesotho, women hope for control of their lives: ravages of AIDS, high unemployment bolster case for legal end to men's deep-rooted dominance. [Online] Available: http://www.aegis.org/news/ct/2004/CT041005.html. [Accessed: 12/03/2009].

GREENE, R.R. 2008. Human behavior theory \& social work practice $\left(3^{\text {rd }}\right.$ ed). New Jersey: Transaction Publishers.

HARSCH, E. 2001. South Africa tackles social inequalities. Africa Recovery, (1):12-19.

HEALTH 24. 2000-2009. Alcohol. [Online] Available: http://www.health.mweb.co.za/mind/ Sexual_dysfunction/1284-1300,13039.asp. [Accessed: 07/03/2009].

HEERY, G. 2001. Preventing violence in relationships. London: Jessica Kingsley.

HUNGERFORD, D., ANDERSON, Z., HUGHES, K., BELLIS, M.A., ANDERSON, P. \& ABBEY, A. 2008. Youth violence alcohol and nightlife. Liverpool: World Health Organization.

KALICHMAN, S.C. \& SIMBAYI, L.C. 2004. Sexual history and risks for sexually transmitted infections among women in an African township in Cape Town, South Africa. AIDS Care, 16(6):681-689.

KRUG, E.G., MERCY, J.A., DAHLBERG, L.L. \& ZWI, A.B. 2002. The world report on violence. The Lancet, 10(5):1083-1088.

KRUGER, A., LEMKE, S., PHOMETSI, M., VAN'T RIET, H., PIENAAR, A.E. \& KOTZE, G. 2006. Poverty and household food security of black South African farm workers: the legacy of social inequalities. Public Health Nutrition, 9(7):830-836. 
LAU, U. 2009. Intimate partner violence. Medical Research Council Fact Sheet: MRC.

LEVIN, J.D. 1995. Introduction to alcoholism counseling: a Bio-psycho-social approach $\left(2^{\text {nd }}\right.$ ed). New York: Taylor \& Francis.

MEEL, B.L. 2006. Alcohol-related traumatic deaths in Transkei Region, South Africa. Internet Journal of Medicine Update, 1(1):1-6.

MOROJELE, N.K., KACHIENG'A, M.A., MOKOKO, E., NKOKO, M.A., PARRY, C.D.H., NKOWANE, A.M., MOSHIA, K.M. \& SAXENA, S. 2006. Alcohol use and sexual behaviour among risky drinkers and bar and shebeen patrons in Gauteng Province, South Africa. Social Science \& Medicine, 62(1):217-227.

OBOT, I.S. 2006. Alcohol use and related problems in Sub-Saharan Africa. African Journal of Drug and Alcohol Studies, 5(1):17-26.

ODEJIDE, O.A. 2006. Alcohol policies in Africa. African Journal of Drug and Alcohol Studies, 5(1):27-39.

PADAYACHEE, A. 1998. The hidden health burden: alcohol-abusing women misunderstood and mistreated. International Journal of Drug Policy, 9:57-67.

PADAYACHEE, A. 2003. Intimate violence and substance (AB) use - the correlative relationship. Acta Criminologica, 16(1):108-114.

PARRY, C.D.H. \& DEWING, S. 2006. A public health approach to addressing alcohol-related crime in South Africa. African Journal of Drug and Alcohol Studies, 5(1):41-56.

PHORANO, O.D., NTHOMANG, K. \& NTSEANE, D. 2005. Alcohol abuse, gender-based violence and HIV/AIDS in Botswana: establishing the link based on empirical evidence. Journal of Social Aspects of HIV/AIDS, 2(1):188-202.

RENZETTI, C.M., EDLESON, J.L. \& BERGEN, R.K. (eds) 2001. Source book on violence against women. London: Sage Publications.

SCOTTISH GOVERNMENT PUBLICATIONS. 2005. Violence against women: a literature review. [Online] Available: http://www.sctland.gov.uk/Publications/2005/03/20895/55141. [Accessed: 04/11/2008].

SOUTH AFRICA'S NATIONAL POLICY FRAMEWORK FOR WOMEN'S EMPOWERMENT AND GENDER. 2000. [Online] Available: www.doh.gov.za/docs/ policy/gender. [Accessed: 12/04/2009].

SWANEPOEL, H. \& DE BEER, F. 2004. Community capacity building. A guide for fieldworkers and community leaders. New York: Oxford University Press.

WEYERS, M.L. 2011. The theory and practice of community work: a South African perspective. Potchefstroom: Keurkopie.

WHO - ETHICAL AND SAFETY RECOMMENDATIONS. 2001. Putting women first: ethical and safety recommendations for research on domestic violence against women. Geneva: World Health Organization.

WHO - MODULE ON GENDER-BASED VIOLENCE. 2005. Integrating poverty and gender into health programmes: a source book for health professionals. Geneva: World Health Organization.

WHO. 2002. World report on violence and health. Geneva: World Health Organization.

Social Work/Maatskaplike Werk 2012:48(3) 
WHO. 2004. Global status report on alcohol. Geneva: World Health Organization.

WHO. 2005. Alcohol and Interpersonal Violence Policy Briefing. Geneva: World Health Organization.

WHO. 2006a. Intimate partner violence and alcohol. Geneva: World Health Organization.

WHO. 2006b. Policy briefing on interpersonal violence and alcohol. Geneva: World Health Organization.

Dr Nomonde Phetlho-Thekisho, Department of Social Work, North-West University, Mafikeng Campus; Dr Elma Ryke, Prof Herman Strydom, School of Psychosocial Behavioural Sciences (Social Work), North-West University, Potchefstroom, South Africa. 